\title{
A FACULDADE DE EDUCAÇÃO DE UMA UNIVERSIDADE PÚBLICA E A AVALIAÇÃO DO TRABALHO DOCENTE: ALGUMAS REPERCUSSÕES
}

\author{
THE COLLEGE OF EDUCATION OF A STATE UNIVERSITY AND THE \\ EVALUATION OF ITS ACADEMIC WORK: SOME REPERCUSSIONS
} LA FACULTÉ D’ÉDUCATION DANS UNE UNIVERSITÉ PUBLIQUE ET
L'ÉVALUATION DU TRAVAIL DES PROFESSEURS: QUELQUES RÉPERCUSSIONS LA FACULTAD DE EDUCACIÓN DE UNA UNIVERSIDAD PÚBLICA Y LA EVALUACIÓN DEL TRABAJO DOCENTE: ALGUNAS REPERCUSIONES

Lúcia Maria Gonçalves de Resende*

\section{RESUMO}

O presente estudo apresenta os resultados de uma pesquisa realizada com o objetivo de analisar as possiveis repercussões da avaliação do trabalho docente desenvolvido na Faculdade de Educação de uma universidade pública, tanto no trabalho pedagógico, como na formação docente. Foi considerado o contexto vivido pela universidade brasileira para interpretar as percepçóes de professores e alunos sobre o trabalho pedagógico desenvolvido por ambos. Alguns encaminhamentos puderam ser apontados como sugestão: viabilizar fóruns de debate; analisar os resultados individual e coletivamente; aperfeiçoar tanto o processo como os instrumentos de avaliação; desenvolver esforços para constituir uma outra cultura institucional de avaliação.

Palavras-chave: Universidade. Avaliação. Formação docente.

* Doutora em Educação pela Universidade Estadual de São Paulo (1998). Professora da Faculdade de Educação da Universidade de Brasília (antorf@terra.com.br). 


\section{INTRODUÇÃO}

Há séculos a matriz dominante estabelece como princípio que o mundo está ao alcance do homem, bastando que ele o observe e experimente. Essa seria a fórmula para atingir a tão aspirada verdade. Porém, o observável e mensurável, por si só, não esgota as possíveis respostas a serem trabalhadas em uma realidade complexa que demanda interpretações criativas, visto ser essa mesma realidade o espaço da imprevisibilidade. As repercussões dessa constatação atingiram as várias áreas do conhecimento e, na educação, princípios pedagógicos já consagrados vêm sofrendo processos de revisão.

Um acentuado estado de revisão instalou-se, sendo vários os apelos que indicam outras concepçôes, auxiliando no entendimento de outras e renovadas relações educativas. No seio das revisões, estão aquelas referentes aos processos avaliativos, nos mais diferentes níveis e modalidades, despertando interesses, estudos e críticas. O presente artigo apresenta os resultados de uma pesquisa que buscou compreender se a avaliação promovida institucionalmente em uma universidade pública é capaz de contribuir para o processo educativo, ou apenas cumpre, burocraticamente, a função de compor um quadro justificador das atuais políticas públicas para a Educação Superior.

Para sustentar as reflexões, alguns eixos teóricos são tratados - o cenário da universidade pública, aspectos da política de avaliação, circunstâncias do trabalho e da formação docente. É nesse locus que serão considerados os processos avaliativos e como podem incidir e interferir no trabalho pedagógico e na formação continuada dos docentes.

\section{UNIVERSIDADE BRASILEIRA:AS ORIGENS DO CONTEXTO DA PESQUISA}

No cenário histórico-social brasileiro, a criação da universidade em sua concepção moderna ocorreu tardiamente - na década de vinte do último século. Segundo Schwartzman (1999), na tradição universitária sempre predominou a concepção humanista tradicional de docência, herança aristotélico-tomista, rigorosamente hierarquizada.

Em 1934, a criação da Universidade de São Paulo pode ser considerada como o primeiro esforço de ruptura com o modelo clássico de universidade. Já no pós-guerra, a industrialização do país demandava recursos humanos qualificados (CUNHA, 1989). O mesmo autor afirma que, nos anos 60, o Governo militar pautou a universidade no modelo desenvolvimentista, reforçando os vínculos entre educação e economia.

A Reforma Universitária re-significou o papel do Estado, que assume o controle de várias instituições e passa a orientar tanto os gastos como os investimentos. Os anos 70 foram marcados pela grande heterogeneidade entre as instituições, uma vez que algumas eram incentivadas a se dedicarem à pesquisa, na condição de centros de excelência, e outras ao ensino. Na década de 80, com a globalização do capitalismo, passa-se do modelo de Estado intervencionista e de bem-estar para o modelo neoliberal, regulador do mercado 
e promotor da competitividade. As implicações para a educação foram os novos espaços e meios de acesso ao conhecimento, mas, também, uma nova determinação dos seus objetivos/fins - o capitalismo contemporâneo demanda um outro tipo de universidade e de profissional. Como conseqüência, a expectativa sobre o trabalho docente associa-se ao embrião regulador e produtivista.

Foi na década de 90 que as principais medidas neoliberais, tanto no setor econômico quanto no educacional, foram tomadas a partir de diretrizes do Ministério da Reforma Administrativa/Mare (SGUISSARDI, 2000). Instalava-se uma outra concepção de universidade, cabendo ao Estado exercer uma função gerencial-administrativa, a partir dos interesses do mercado capitalista globalizado.

No início do século XXI a universidade vive a definição de uma reforma universitária controvertida, porque permeada pelas contradiçôes de seu tempo. A educação superior no Brasil vive um momento crítico, pois seus fundamentos institucionais estão sendo questionados por diversos setores sociais. Isso se explica tendo em vista as rápidas e profundas transformações e a própria necessidade de recomposição de correlação de forças entre Estado, sociedade e mercado. Nessa perspectiva, entre tantas outras questôes, a avaliação do trabalho e a formação continuada dos docentes tendem a sofrer significativas revisões.

Segundo Heymann e Alberti (2002), na segunda metade dos anos 90 desencadeou-se um forte processo de ajustamento do projeto político nacional à nova ordem mundial, repercutindo na educação superior. Mais especificamente, o setor público viu-se imerso em sérias restrições orçamentárias, com a restrição histórica da esfera pública, o que marcou ainda mais a expansão da esfera privada. Como conseqüência, a atividade de ensino reforça-se como principal foco de definição dessa política.

Na perspectiva de Chauí (1999), não é possível uma universidade pobre em recursos e, acima de tudo, voltada quase exclusivamente para o mercado reverter as atuais dificuldades. A reestruturação administrativa do Estado, verificada a partir de 1995, valeu-se dos propósitos da racionalização e da modernização da máquina pública, transformando as instituições sociais em organizações, enfatizando seu caráter de instrumentalidade, de gestão de recursos e estratégias de desempenho. A autora classifica três tipos de universidade: anos 70 - universidade funcional - adaptou-se ao mercado, alterando currículos e programas; anos 80 - universidade de resultados - prioriza utilidades imediatas exigidas pelo mercado; anos 90 - universidade operacional - caracterizada pela eficácia de suas ações.

Segundo Sevcenko (2000), mais do que nunca, a lógica operacional configura a universidade como objeto de disputa em um campo marcado pela heterogeneidade das instituições que o compõem. Nas universidades brasileiras, prevalece o modelo de administração eficiente, capaz de gerar seus próprios recursos com nexos cada vez maiores com o mercado e a corrida tecnológica. A eficácia do desempenho é medida em termos de sucessos estatísticos, produtividade e visibilidade, para atrair novas parcerias, dotaçôes e investimentos. 
Considerando esse contexto, Trigueiro (2000) sustenta que a tarefa de modernização da educação superior no Brasil está vinculada ao setor privado, voltado, principalmente para o atendimento ao mercado e sua expansão física. Sob esse ângulo, a rede privada estaria se tornando a responsável pelos novos perfis dos profissionais que ingressam no mercado de trabalho, com currículos mais "ajustados" às demandas.

$\mathrm{O}$ meio acadêmico vem formulando críticas em relação à política educacional para a educação superior. Silva Júnior e Sguissardi (2000), por exemplo, defendem que as políticas públicas na última década orientaram-se pelo paradigma da oferta do Estado, influenciadas por organismos internacionais e não pela demanda da sociedade. Segundo essa compreensão, o Estado partiu da idéia de que a educação superior pode ser oferecida por quem quiser e puder, desde que se habilite às regras definidas pelo poder público e às recomendações oriundas do Banco Mundial. Nesse cenário, a docência universitária tem enfrentado contradiçôes e propostas avaliativas que colocam em xeque o trabalho docente.

\section{UNIVERSIDADE OPERACIONAL E AVALIAÇÃO}

Em um contexto no qual a docência passa a ser compreendida no âmbito da mera e rápida transferência de saberes, os processos de avaliação de trabalho tendem a confinar-se na mesma matriz e lógica. No âmbito da universidade, merece destaque o Sistema Nacional de Avaliação do Ensino Superior (Sinaes), que abrange as avaliaçôes das instituições de nível superior em aspectos físicos, metodológicos e formativos, entre outros. Abrange, ainda, a aplicação de provas a alunos iniciantes e concluintes.

A Capes, desde 1977, tem avaliado os programas de pós-graduação, com planos para a avaliação de professores de diversos níveis de ensino. Assim também, as próprias instituições acabam criando mecanismos para avaliar, por exemplo, o desempenho de seus docentes. Enfim, são diferentes procedimentos adotados para planejar e executar um sistema de avaliação, da dimensão que se tem visto em nosso país, demandando grande investimento financeiro e esforços dos programas. Para Dalben (2004), essas avaliações servem de suporte para a elaboração de políticas públicas, entre outros objetivos. A sistemática de avaliação desenvolvida pelo governo federal tem se justificado como necessária para oferecer referências à sociedade e parâmetros de análise e comparativos, nas diferentes realidades brasileiras.

Paralelamente, cabe analisar os objetivos dos sistemas avaliativos, pois, em uma economia liberal cuja mola-mestra é o mercado, interesses que não os educacionais podem delinear processos e priorizar condutas. Um dos campos que tende à desvalorização, obviamente, refere-se às atividades de pesquisa. Em uma instituição que tende a reduzirse à gestão de receitas e despesas, a docência volta-se à habilitação rápida dos discentes, que precisam ingressar no mercado de trabalho. Essa perspectiva perversa pode reduzir o trabalho docente à transmissão de saberes e ao adestramento. 
As transformações que vêm ocorrendo nas políticas educacionais, como aquelas orientadas para a educação superior e, conseqüentemente, para a docência universitária no Brasil, precisam ser compreendidas no contexto da reforma do Estado. A lógica da reforma revela seu caráter contábil e produtivista, além de assentar-se na ênfase da eficiência administrativa e da produtividade, em detrimento da acadêmica.

A política de terceirização e privatização interna da esfera pública tem diversas situações de difícil solução, principalmente quando se considera a necessidade de garantir à universidade um projeto que valorize a articulação entre o ensino e a pesquisa. A universidade pública vem convivendo com muitas dificuldades, contando com um crescente número de professores substitutos que, sem vínculo efetivo com a instituição, acabam por revelar menor envolvimento com projetos acadêmicos diversos.

A perspectiva neoliberal assumida pelo Estado tem acarretado a configuração de uma docência exercida sob relações precárias de trabalho, com pouco apoio financeiro e administrativo para o ensino, a pesquisa e a extensão, promovendo conhecimento aligeirado, voltado para necessidades de um mercado voraz. Além disso, está subordinada a sistemas de avaliação permeados por lógica perversa e antropofágica, de conseqüências graves para a própria autonomia da e na produção do conhecimento.

A legislação em vigor desencadeia uma docência pautada em critérios nos quais predominam quantidade, tempo e custo de produção, contribuindo para a configuração de um trabalho produtivista. Segundo Sevcenko (2000), o docente ideal é um híbrido de cientista e corretor de valores, dedicando seu tempo a preenchimento de relatórios, alimentando estatísticas, levantando verbas e promovendo visibilidade para si e para seu departamento. $\mathrm{O}$ campus vai se configurando num gigantesco pregão. Há prevalência quantitativa em detrimento da qualitativa na produção do trabalho intelectual, que se centra no individualismo e na competição.

Pressionada pela insuficiência de recursos e pela crescente demanda por aposentadorias, a universidade pública sofre a redução de recursos, até mesmo para a reposição de seus profissionais, pela falta de concursos públicos. A medida paliativa adotada tem sido a contratação de professores-substitutos e/ou cedidos de outros órgãos. Fica caracterizada a docência pontual, rotativa, com frágeis "raízes" institucionais e uma remuneração não condizente com o verdadeiro papel do docente universitário.

\section{DOCÊNCIA UNIVERSITÁRIA NA RELAÇÃOTRABALHO, EDUCAÇÃO E FORMAÇÃO}

A relação que envolve trabalho e educação é crítica e, na opinião de Ratinoff (1995), pode alterar a própria ética do trabalho, que corre o risco de desaparecer para dar lugar a uma visão mais fatalista e oportunista. A abundância de mão-de-obra afeta a ética do trabalho, visto que começa a fazer pouco sentido continuar acreditando nas recompensas de uma atividade bem qualificada, quando as oportunidades de trabalho e ascensão profissional se mostram tão improváveis. 
E como se coloca, nesse cenário, o trabalhador na e da educação? Que repercussões acarreta para esse segmento? Cabe questionarmos se as propostas e os processos de avaliação do trabalho docente têm buscado superar modelos que aprofundam diferenças, pelo discurso instituído da competência. Segundo Chauí (2000), esse discurso confunde-se com a linguagem autorizada, via interlocutores previamente reconhecidos pelo direito de fala, com circunstâncias predeterminadas, nas quais conteúdo e forma já foram devidamente autorizados.

Tomando o discurso da competência como o do conhecimento, fica fortalecido o caráter ideológico e dissimulador de dominações e interferências das mais diversas esferas, micro e macro, inclusive as internacionais, centradas em eixos de predominância econômica. $\mathrm{O}$ trabalhador intelectual formado em uma realidade monitorada e impregnada de princípios, que não os de inclusão, pode reforçar a condição de objetos sociais e não de sujeitos históricos - mediatizantes e mediatizados.

São significativas as contribuições apresentadas por pesquisadores sobre a formação docente. Num recorte histórico, tomo a década de 80 , como tempo e espaço de análise sobre a formação docente pelas seguintes razões: por um lado porque, conforme Frigotto (1999), ao discutir as reformas educativas no Brasil, essa década configura-se pelas constantes mudanças no cenário político-econômico e social, e pela reorganização da sociedade civil, que conclamou pelo exercício da cidadania e fortalecimento da democracia através da ampliação da esfera pública, como garantia dos direitos sociais. Os embates travados sobre formação docente buscaram privilegiar o caráter político da prática pedagógica e o compromisso do educador. Esse quadro que se apresenta, no início da década de 80 , articula-se com as representaçóes mais amplas da sociedade brasileira face à superação do autoritarismo implantado a partir do governo militar e da construção de novos caminhos, face à redemocratização do país. Nesse momento, ganham força estudos que denunciam o caráter reprodutivista da educação, buscando anunciar condições de enfrentamento nas condições de trabalho, salários e, conseqüentemente, de revisão da prática pedagógica.

Problemas diversos emergem com a ampliação sem critério e planejamento, semelhante ao que vivemos com a atual expansão pós-LDB, na década de 90 , reafirmando a crise de identidade profissional, a diminuição de salários e, conseqüentemente, a reorganização do trabalho em função da descaracterização da docência. É com base na divisão técnica do trabalho que os professores são compreendidos como tarefeiros, cumpridores de programas e conteúdos fragmentados.

No cenário internacional, a partir das décadas de 80 e 90, tanto na América do Norte quanto na Europa, as pesquisas sobre formação de professores ganham destaque no que se refere ao movimento de profissionalização do ensino, que discute aspectos relacionados a reformas educativas, formação, profissionalização, prática reflexiva como constituinte do exercício profissional, epistemologia da prática, identidade, saberes da docência e 
história de vida dos professores. Apesar do cenário já descrito, as discussões que se consubstanciam nessas duas décadas no Brasil consolidam o discurso acadêmico de valorização da pesquisa tanto em relação à formação de professores quanto ao desenvolvimento profissional. Esse discurso contra-hegemônico articula-se com categorias teóricas no campo dos saberes docentes, identidade e história de vida como tempo e espaço de formação inicial e continuada, profissionalização, desenvolvimento pessoal, bem como em relação às possibilidades teórico-metodológicas da pesquisa na área educacional.

\section{PISTAS SOBRE A INVESTIGAÇÃO}

O estudo partiu de um quadro problematizador que fez emergir questionamentos: como se desenvolvem os mecanismos de avaliação do trabalho docente no atual cenário? $\mathrm{O}$ que esperar de seus reflexos? Como instalar procedimentos avaliativos que revertam para a melhoria da qualidade da docência e não para a contabilidade de realizações?

Inicialmente buscamos focalizar a instituição pesquisada, entendendo que o habitus indica, segundo Bourdieu (1983), tanto um conhecimento adquirido e uma disposição incorporada, como também uma postura de "agente em ação", não se constituindo produto de um cálculo teórico, mas de estratégias práticas. Esse habitus, anterior ao indivíduo, indica condutas 'razoáveis' e/ou 'absurdas' orientadoras de ações.

\section{O campo investigado}

A universidade pesquisada foi criada como instituição Federal em 1961, antecipando a reforma universitária, tendo sido instalada como fundação. Contradições estão presentes desde sua origem, pois, apesar de justificar-se por um discurso de criação modernizante, em certo sentido, associou-se à burguesia nacional, que necessitava de um quadro de técnicos dirigentes e mão-de-obra qualificada. Nessa perspectiva, é possível afirmar que, na dinâmica de criação, foi veiculado um discurso contraditório, que enfatizava o nacionalismo agonizante e um projeto de desenvolvimento industrial autônomo.

Com a promulgação da Reforma Universitária - Lei 5.540/68 -, ocorreu uma transformação fundamental na organização e estrutura do ensino superior no Brasil: a criação do departamento como menor célula da universidade, contribuindo para uma fragmentação. Até esse momento, a universidade pesquisada era organizada apenas em torno de "Faculdades" que ofereciam um ou vários cursos de áreas específicas e abrigavam seus respectivos professores. É nesse contexto, portanto, que surge um modelo universitário que ainda persiste. Atualmente, a Faculdade de Educação possui três departamentos: Métodos e Técnicas; Planejamento e Administração; e Teoria e Fundamentos, e oferece a graduação em Pedagogia e o Programa de Pós-graduação - especialização, mestrado e doutorado. Segundo informações colhidas na secretaria acadêmica, conta atualmente com 108 professores, sendo 66 professores do quadro regular, 23 professores cedidos pela Secretaria de Educação do Distrito Federal e 19 professores substitutos. Os discentes totalizam aproximadamente 2.600 alunos. 


\section{OS PROCEDIMENTOS DA PESQUISA}

O estudo abarcou professores e alunos que se envolveram em processos avaliativos institucionalizados na faculdade, no período de 2005 a 2006. Analisamos a ficha de avaliação utilizada pelo discente e pelo docente para coletar as percepções que possuem sobre a proposta avaliativa do trabalho docente. Assim, foram aplicados três tipos de questionários: um para docentes em processo avaliativo por mérito, um para docentes em progressão funcional por tempo de serviço, e outro para discentes que participaram de processos avaliativos de docentes.

Foram identificados 28 docentes do quadro regular, distribuídos nos três departamentos, que passaram por progressão funcional no período de 2005 a 2006. Desses, 13 por mérito e 15 por tempo de serviço. Trinta discentes participaram como interlocutores da pesquisa, distribuídos em diferentes semestres no curso de Pedagogia.

Pesquisar processos avaliativos num contexto em crise demandou a busca de possibilidades que potencializaram a escuta sensível dos interlocutores - professores e alunos -, no sentido de melhor entender o entrecruzamento das intençóes e do aprendizado contínuo dos saberes, da identidade e da professoralidade e, mais especificamente, da análise dos significados implicados no processo de investigação.

Foi com base no entrecruzamento teórico-empírico que buscamos entender as implicaçōes do processo avaliativo do trabalho docente. Para tal, o estudo das trilhas e trajetórias empreendidas possibilitou melhor apreender a importância e singularidade atribuída aos significados, para compreender a epistemologia da avaliação, formação e organização do trabalho pedagógico.

\section{A BUSCA DE EXPLICAÇÕES E ANÁLISES}

Antes de analisarmos os processos avaliativos, fez-se necessário compreender "as regras do jogo" nas quais os docentes interagem. Para tanto, não nos limitamos a analisar apenas os docentes que foram avaliados por seus méritos, mas também aqueles que, por diferentes razões e mesmo tendo direito, não se submeteram a essa avaliação, ao longo do período de dois anos - 2004 a 2005. Dessa maneira teríamos condições de identificar por que alguns deles não participaram do processo que oportuniza a progressão funcional e como o grupo envolvido percebe o processo avaliativo em suas repercussóes no trabalho pedagógico. Foram vários os achados; alguns esperados, outros menos, mas ambos desencadeadores de análises e possibilidades de revisão de concepções, sistemáticas e instrumentos de avaliação.

O grupo de docentes investigados pode ser considerado experiente e familiarizado com a cultura universitária e da instituição onde atuam. Possuem de 10 a 23 anos de magistério e na Faculdade de Educação atuam entre oito e 21 anos. São períodos de 
tempo que nos permitem inferir que boa parte dos interlocutores vivenciou a sedimentação de modelos universitários fundados em princípios operacionais, principalmente no que se refere à avaliação do trabalho docente, ou, mais especificamente, do controle da produtividade.

Trata-se de um docente que convive, segundo Thayer (2002), menos com as contingências que eventualmente qualquer universidade sofre - crise disciplinar, lingüística, orçamentária, de autonomia etc. - e mais com a quebra do sistema de limites e de categorias que constitui a chamada "arquitetônica moderna".

Mesmo possuindo a formação inicial voltada para a docência e tendo concluído mestrado e doutorado, $45 \%$ dos docentes não consideraram significativa a contribuição dos cursos de formação inicial e continuada para a docência na Educação Superior. Cabe, portanto, observarmos que o bacharel atuando na docência possui uma formação inadequada, pelo fato de ter sua formação, basicamente, em conhecimentos específicos da área de atuação profissional, que não a pedagógica. Porém, ocorre que, no caso dos interlocutores da pesquisa, todos fizeram cursos que prepararam para a docência, focados na educação e, mesmo assim, quase a metade dos interlocutores não se sente preparada para a docência universitária. Reconhecemos as especificidades que a Educação Superior impõe, mas também parece importante analisar que alguns princípios pedagógicos e didáticos podem pautar diferentes níveis de ensino nos quais os docentes atuam. Caberia, nessa perspectiva, desenvolver outros estudos a respeito dessas especificidades, para além da dicotomia bacharelado/licenciatura.

Possivelmente, um dos aspectos que agrava o entendimento sobre o despreparo para a docência na educação superior esteja voltado para a maneira como as necessidades didáticas dos docentes são tratadas no âmbito da própria universidade, distante da perspectiva do trabalho pelo e no coletivo. Os discursos acadêmicos ressaltam a necessidade da constituição desse corpus, mas, contraditoriamente, é patente o isolamento docente na universidade. Se, de um lado, ensino, pesquisa e extensão demandam uma importante articulação pautada no princípio do coletivo, pelo docente e entre pares, por outro, os docentes acabam consolidando, em boa parte de suas ações, atos acadêmicos solitários, marcados pelo isolamento, que possivelmente esteja assentado na massificação do ensino e na própria territorialização do conhecimento.

Nesse aspecto, a própria faculdade poderia desencadear projetos que buscassem, por exemplo, o exercício do coletivo e de espaços de convergência acadêmica. Mas o panorama encontrado parece compatível com o isolacionismo, sendo nesse cenário que se encontram os processos avaliativos e que, coerentemente, também são pautados na individualidade, sem fóruns de discussão e com pouca repercussão no coletivo. Os espaços e tempos que poderiam ser considerados coletivos, como nas reuniōes de diferentes colegiados, as discussões e reflexões centram-se em focos administrativos, burocratizados e burocratizadores. 
Os $52 \%$ dos interlocutores que afirmaram se sentir preparados para a docência na educação superior alegaram que a criticidade e a qualidade dos cursos por eles realizados vêm oportunizando uma docência de boa qualidade. O entendimento que marcou o grupo desses docentes pautou-se na relação entre docência universitária, conteúdo teórico e compromisso profissional. Não foi objetivo desta investigação aprofundar entendimentos sobre a gênese que constitui a profissão docente, no entanto, cabe deixar como foco de futuras reflexões e estudos as percepções que os docentes possuem sobre desenvolvimento da docência universitária e, principalmente, os significados que constroem, na condição de atores e autores da ação docente.

Os docentes pesquisados possuem uma carga horária de trabalho de 40 horas, com dedicação exclusiva, que a maioria distribuiu em 12 horas para o ensino, 10 horas para pesquisa; quatro horas para extensão, quatro horas para orientação de alunos e 10 para administração. Porém, consideraram que esta é uma distribuição genérica, pois acabam dedicando mais horas às atividades que aquelas previstas contratualmente (40 horas).

É interessante observar que o tempo dedicado às questôes administrativas supera o de extensão e atendimento ao aluno. É surpreendente como os docentes acabam tendo que canalizar o foco de sua atuação para o que poderíamos chamar de burocratizado. Segundo Vázquez (1977), a exteriorização ou formalismo da prática é o traço mais característico do burocratismo. Tomados por práticas que os absorvem em reuniōes departamentais, de área e linha de pesquisa, comissões etc., os docentes rendem-se a atividades que se subalternam à forma e preexistentes ao conteúdo. Dois interlocutores mencionaram o tempo que "perdem" analisando processos, semelhantes a tantos outros, mas que dependiam dos ritos administrativos e burocráticos da constituição de comissões, reuniōes e discussões. Os atos práticos acabam se transformando em roupagens que revestem práticas pré-existentes. A práxis se burocratiza onde quer que o formalismo ou o formulismo dominem, ou quando o formal se converte em seu próprio conteúdo. Na prática burocratizada o conteúdo se sacrifica à forma, o real ao ideal, e o particular concreto ao universal abstrato (VÁZQUEZ, 1977).

Talvez pudéssemos nos referir a um tipo de atuação degradada, não criativa, que atende a ritos, plasmando formas não apontadas por conteúdos, mas por normas. Os atos burocratizadores acabam incomodando os docentes, mas parecem possuir uma sobrevida, alimentados por engrenagens que os ratificam e sustentam. É evidente que reconhecemos a necessidade de que os docentes participem de encaminhamentos que a burocracia acadêmica demanda; é a regra de um jogo marcado por princípios da participação democrática e da representação. O que estamos destacando é o grande volume de atribuições burocratizantes e burocratizadoras que os docentes acabam assumindo e com as quais vão consumindo seu espaço/tempo na universidade. Ratificando nossa posição, dois docentes chegaram a dizer que "alguns profissionais que ocupam cargos de direção, chefia e/ou coordenação parecem 'azeitar' a máquina para fazê-la continuar movimentando-se em lugar de viabilizá-la no sentido de sua agilização, para torná-la mais competente e significativa”. 
A Faculdade de Educação, possivelmente como outras unidades acadêmicas, avalia de maneira frágil e incompleta o trabalho docente. Na verdade, a avaliação acaba sendo um mecanismo capaz de representar as bases de sustentação do entendimento de que na educação o profissional docente é mais um instrumento de ratificação da operacionalidade e do mercantilismo.

Não há dúvida de que os docentes percebem e tentam resistir às imposições, mas quase sempre são vencidos pelo ativismo acadêmico. Prova disso foi o fato de que alguns professores deixaram de encaminhar o processo de progressão funcional por mérito, alegando "falta de tempo para cumprir mais uma burocracia". O "por quê" participar do processo avaliativo acaba subjugando-se às regras do "como" participar.

Os fatos parecem indicar que, no final da década de 90 e no início da presente década, foram se tornando mais claras duas vertentes: a ausência de projetos norteadores que respondessem de maneira efetiva às funções da universidade pela própria universidade $\mathrm{e}$ o acompanhamento da onda mercadológica. A perspectiva que sustenta processos avaliativos possui, invariavelmente, essa marca, privilegiando o caráter quantitativo na atuação do docente universitário.

Retomamos Chauí (2000), para expressar que os interesses privilegiados por políticas públicas de cunho mercadológico e neoliberal, transformando a instituição universitária em organização universitária, criam um ambiente avaliativo que despreza princípios construídos historicamente. São as iniciativas externas descaracterizando anseios acadêmicos dos docentes e da universidade como um todo.

As políticas públicas definem critérios e prioridades que afetam comportamentos e até mesmo financiamentos, que Segundo Freitas (2003), acabam por fechar o circuito. As políticas apontam processos de avaliação, privilegiando recursos em função dos resultados do processo avaliativo. O Estado avaliador usa esse tripé como um mecanismo para passar os seus projetos políticos, por um lado, e, por outro, para exercer o controle da adequação das instituições aos projetos políticos, a partir do tripé: políticas, avaliação e distribuição de recursos. Não se trata de um fenômeno novo. Nos anos 80 , a intervenção de organismos internacionais, como FMI, BID etc., é sentida nas instituições brasileiras, com projetos de uma agência de avaliação específica, controlando e articulando ações no âmbito nacional e propostas avaliativas.

Em relação às condições de trabalho como aspecto que interfere na qualidade do trabalho docente, $38 \%$ dos docentes consideraram que as salas de aula e os materiais didáticos disponíveis estão adequados. Mas, para 51\%, a faculdade deveria melhorar nesses quesitos. Há ainda uma diferença de opinião entre os interlocutores no que se refere à sala de trabalho, destinada às atividades fora da carga horária de ensino. Para $68 \%$ dos interlocutores, sua sala de trabalho é insuficiente e deficiente; no entanto, para os demais é boa e ótima. Qual seria a causa de opiniōes tão divergentes? A resposta a este questionamento pode estar ligada à grande discrepância entre a qualidade dos locais de 
trabalho, refletindo a inadequação da distribuição de espaços físicos e a conseqüente diferença nas condições de trabalho.

Ao serem perguntados especificamente sobre o processo de avaliação institucionalizado na faculdade para a obtenção de progressão funcional, $71 \%$ consideraram o processo burocratizado, $16 \%$ inadequado e $13 \%$ positivo. Os docentes que demonstraram um olhar positivo sobre o processo (13\%) consideram que sempre é possível levar em consideração os resultados que aparecem nos relatórios. Mesmo assim reconhecem que seria necessário repensar a sistemática do processo de avaliação. Entendem que seria necessária uma ruptura com o processo instituído.

Tais rupturas sugerem inovações, que no todo societário têm aparecido de forma acelerada e espraiando-se nos mais variados setores da vida humana. Entretanto, a universidade parece tender para a defesa de interesses internos, acomodaçōes, conservadorismos, sugerindo até mesmo corporativismos. Se a norma prevê a avaliação do trabalho docente, avalia-se... avalia-se?

Quando perguntados se o processo avaliativo poderia contribuir com a formação continuada do docente, $66 \%$ deles afirmaram que não. São números que destacam a necessidade de a universidade definir clara e substantivamente uma política de avaliação e de formação de profissionais da educação, cuja proposta básica seja a articulação da especificidade do trabalho docente com a investigação do conhecimento historicamente produzido e as tecnologias e inovaçôes demandadas pelo mundo contemporâneo.

Quanto ao grupo de docentes que optou por não participar do processo avaliativo por mérito, algumas justificativas foram apontadas e centraram-se no argumento de que se tratava de um processo trabalhoso e que não realizava uma avaliação. As sugestões para superar o processo de avaliação são apontadas como algo a ser revisto, sendo um equívoco pensar de maneira fragmentada a avaliação. É fundamental que a comunidade acadêmica compartilhe os resultados de avaliação. Esse é o entendimento generalizado do grupo de interlocutores e que reflete a insatisfação dos docentes da faculdade com relação ao processo avaliativo. O grupo necessita, contudo, de ter a capacidade de conceber e propor processos que realmente atendam a princípios avaliativos promotores de formação e revisão do processo educativo.

Entre os alunos, $87 \%$ não entendem que o processo de avaliação do trabalho docente seja positivo. De forma geral, consideraram oportuna a criação de fóruns de debate, pautados nos resultados de avaliações, para promover a melhoria das atividades acadêmicas. A grande maioria afirmou que somente se houver um programa que analise os resultados das avaliações, coordenado pela $\mathrm{FE}$, os docentes em geral poderão ficar mais abertos para rever posturas e re-significar seu trabalho.

Os discursos progressistas que fluem entre docentes e discentes poderiam encontrar terreno fértil em tempos e espaços propícios para discutir a avaliação do trabalho 
educativo. Contudo, qualquer processo desencadeador de transformações que não parta do habitus ou do instituído pode gerar o voluntarismo pedagógico e o discurso teórico vanguardista, concomitante a uma atuação conservadora e ultrapassada. O que pouco contribui para gerar outras práticas é a ênfase na denuncia de culpados, grupo no qual sempre se encontra a figura dos professores.

Quanto à necessidade de revisão da sistemática e dos instrumentos, destacamos que a faculdade, há algum tempo, vem tomando iniciativas no sentido de desencadear revisōes no processo avaliativo do trabalho docente. Ao posicionar-se, questionando o processo avaliativo e seus instrumentos, por apresentarem natureza meramente quantitativista e classificatória, comprometeu-se a sugerir outras alternativas. Alguns esforços foram feitos nesse sentido, no entanto ainda não se efetivaram.

\section{CONSIDERAÇÕES FINAIS}

Deus me livre se acreditasse que sou bom ou mau professor pelos seus resultados. A sociedade tem de ter os seus freios e contrapesos meritocráticos: senão a democracia degenera em demagogia e em anarquia. Ainda teremos um dia os argüidos a votar sobre a qualidade das sentenças dos juízes... (LAUAND, 2004, p. 37).

O objetivo do presente estudo foi analisar a avaliação do trabalho docente, identificando possíveis repercussões. Desde o início da investigação tive a clareza de que a abordagem sobre o ato de avaliar poderia acarretar desconfianças, curiosidades e conflitos geradores de interpretaçóes, ora justificadoras, ora desencadeadoras de posicionamentos de resistência. Mas o que mais me animou a desenvolver o estudo foi a possibilidade de desencadear discussões carregadas de intenções revisionistas, rumo à busca da melhoria do trabalho pedagógico na Faculdade de Educação de uma universidade pública.

$\mathrm{Na}$ verdade, a avaliação exerce um papel central nas eventuais revisões de trabalhos individuais, institucionais e na sociedade de maneira geral. Em contrapartida, algumas tensōes podem tocar interesses individuais e/ou coletivos, que afrontam entendimentos e culturas institucionais cristalizadas. Para Popkewitz (1992), tensões, conflitos e ambigüidades são práticas que se relacionam com fins sociais. Daí por que processos avaliativos podem ter implicações que conduzam a tomadas de decisão.

A exemplo de outros autores, Dias Sobrinho (2002) afirma não haver avaliação neutra, exatamente por não existir um modelo único, fazendo com que os processos sejam distintos. Invariavelmente acontece uma relação singular entre os atores envolvidos, de maneira que a implicação adquire significação própria. E se não existe neutralidade, é indispensável que as intencionalidades sejam conhecidas e compreendidas pelos sujeitos que se envolvem no processo. A esse respeito, Leite (2002) insiste na necessidade de conhecer as concepçôes dos formatos de avaliação para entender e decifrar suas vinculações a diferentes pressupostos. 
A investigação apontou que há divergências e entendimentos convergentes sobre as intencionalidades que permeiam os procesos avaliativos institucionalizados na Faculdade de Educação pesquisada. Não seria um processo simples o exercício coletivo de análise da forte polarização entre concepções de educação superior e propostas de avaliação do trabalho docente. Os formatos analisados na presente investigação pertencem ao enfoque político do liberalismo ou, como querem alguns, ao neo-liberalismo, divergindo na distribuição do grau de democracia que poderá ser menos ou mais representativa. São formatos que muitas vezes conseguem ser aceitos pela burocracia de Estado e por boa parte dos profissionais. Basta refletirmos sobre o fato de que em toda a universidade de Brasília apenas a Faculdade de Educação recusa formalmente a proposta e o instrumento de avaliação do trabalho docente.

A universidade em questão, assim como boa parte das universidades federais, continua respondendo pela cultura de subalternidade e submissão a processos avaliativos que emergem de mão única do Estado, regulando-a e moldando-a conforme formatação exigida. Nesse cenário, o formato de avaliação emancipatória (SAUL, 2000) encontra pouca repercussão, inclusive como resultado de um processo cumulativo de produção de conhecimentos em nível de teoria de avaliação educacional. Para Leite (2002), esse formato mantém a figura do especialista em avaliação como orientador do processo. Por outro lado, o projeto de uma avaliação "orientadora", em geral, utiliza a metodologia da pesquisa-ação, na qual o envolvimento dos sujeitos é uma constante. Cabe ressaltar que "emancipação, decisão democrática, transformação e crítica educativa" são os principais conceitos envolvidos nesta proposta. E, convenhamos, trata-se de uma mudança radical na cultura avaliativa das instituições.

E, nesse momento da reflexão, ganha ênfase a consolidação do Projeto Políticopedagógico institucional e de curso, atrelado a processos avaliativos participativos, cujos sujeitos devem ser gestores, membros da comunidade universitária, representantes eleitos, com o objetivo de instaurar uma avaliação, tanto institucional, como de seus trabalhadores, marcada por mediação, negociação, transformação, transparência, legitimidade e decisão coletiva. A metodologia é basicamente ativa, de co-gestão e fóruns privilegiados de discussão.

Mas como combinar a realidade constatada com a utopia de uma universidade democrática e uma avaliação participativa?

Se existe possibilidade de haver uma conexão entre avaliação, modelo de universidade, planejamento e assessoramento pedagógico, uma coisa é certa: será fundamental que o grupo esteja disposto a rever posturas e armar-se de coragem para viver rupturas. Porém, de fato, pouco convivemos com a gênese desse formato participativo, nas mais diversas instituições - educacionais, familiares e/ou sociais, mesmo que há tempos tenhamos incorporado discursos que o legitimam.

A tendência tem sido aceitar o modelo institucionalizado, abstendo-se de uma resistência que se confronte com formatos avaliativos compulsórios, que priorizam a 
produtividade individual. Mesmo que a Faculdade de Educação tenha se rebelado contra o modelo de avaliação imposto institucionalmente, diante da abertura dada para propor outro formato, acabou não gerando um processo que concebesse uma proposta, com predominância qualitativa e outras concepçôes de docência. Na verdade, a crítica que não se plasma acaba sendo inócua, inconsistente e frágil para desencadear mudanças. Em outras palavras, há o favorecimento da estabilidade de um determinado formato de avaliação, o qual pode estar retardando as antigas reivindicações de inspiração autonômica e autogestionária dos docentes do ensino superior.

Daí por que ser importante observar a força do habitus e da institucionalização. Para Bourdieu (1991), práticas duradouras, que funcionam como princípios geradores e organizadores, mesmo que não sejam sujeitas à regulação e à regra, produto da obediência, podem ser coletivamente seguidas, orquestradas, mesmo que sem o maestro.

Alguns encaminhamentos poderiam ser dados na direção de argumentos que defendam processos avaliativos capazes de oferecer ao docente e aos discentes subsídios para a auto e hétero avaliação do trabalho educativo, buscando o auto-conhecimento humano e profissional. Uma avaliação que signifique estímulo à educação continuada, e não tribunal de julgamento.

Nessa direção, alguns pressupostos poderiam induzir a definição dos objetivos:

- criar espaços e tempos coletivos destinados à análise dos processos avaliativos;

- oferecer subsídios ao docente para o auto-conhecimento e crítica do processo educativo que desenvolve (auto-crítica), por meio de uma cultura de avaliação;

- subsidiar a permanente reconstrução do trabalho pedagógico, em cada disciplina, para promover a identificação e inserção adequada no projeto do curso;

- oportunizar aos alunos espaços de manifestação e de participação na construção do trabalho pedagógico da disciplina e no desenvolvimento do projeto do curso.

São necessárias outras etapas para avaliar os diferentes aspectos do trabalho pedagógico, como o contexto em que se desenvolve e o acompanhamento de egressos e a eficácia das disciplinas do curso no seu exercício profissional, o que poderia desencadear uma cultura de acompanhamento de egressos e de avaliação da repercussão social do curso.

Para o desenvolvimento de um programa permanente de avaliação do trabalho pedagógico, algumas sugestôes podem ser apontadas:

- sistematização de instrumentos avaliativos que contemplassem os vários estudos realizados para a alteração dos já existentes, para a análise, pela Câmara Setorial de Graduação;

- aplicação imediata, em caráter experimental, de um novo formato de instrumentos, de modo que sejam utilizados nos processos de progressão funcional dos docentes;

- constituição de uma comissão permanente de avaliação do trabalho pedagógico, com os objetivos de: 
- viabilizar os fóruns de debate sobre os processos avaliativos;

- analisar os resultados oferecidos pelos instrumentos;

- aperfeiçoar o processo de avaliação;

- identificar os aspectos/procedimentos que vêm obtendo sucesso, para que sejam socializados;

- sugerir ações com vistas a superar os aspectos limitadores identificados na avaliação;

- planejar e implementar outras etapas do processo avaliativo;

- e desenvolver esforços para construir uma outra cultura institucional de avaliação.

Sem dúvida, muitas das análises puderam acentuar a crise da universidade, na medida em que o trabalho desenvolvido foi identificado pelo seu caráter mercantilista. No processo de avaliar o trabalho docente e no reordenamento das formas de como lidar com o conhecimento, alguns conceitos inerentes ao pensar e fazer pedagógicos precisam ser redimensionados. Um deles é o próprio conceito de intelectual e de docente universitário, sem considerar esvaziadas de sentido as concepçōes já formuladas.

A avaliação do trabalho docente não é nova, mas o que pode ser mudado são os seus objetivos. Com frequiência, é vista como processo secreto, verdadeiros inquéritos, mas deveria ocorrer nos diferentes espaços e tempos onde acontece o processo educativo e não em momentos episódicos e, ainda, no âmbito de uma avaliação institucional mais ampla.

É preciso reforçar que a crise da universidade brasileira não está “ilhada” em sua própria origem, mas advém de projetos sociais planejados e executados, visando conter determinadas pressóes e insatisfações, ao mesmo tempo em que é veiculado um discurso democrático acerca das práticas avaliativas e de formação de discentes e docentes. Dessa forma, os achados que obtivemos possivelmente encontram respaldo em outras universidades federais.

E, para finalizar, retorno à epígrafe das considerações finais e analiso que caberá à própria universidade de Brasília e, em especial, à Faculdade de Educação construir de maneira coerente e madura processos que possam avaliar os "méritos" do trabalho docente, sem propostas demagógicas que o degenerem. E, então, talvez seja possível interferir na própria qualidade das "sentenças dos juízes"...

\section{Referências}

BOURDIEU, Pierre. Questôes de sociologia. Rio de Janeiro: Marco Zero, 1983. . Coisas ditas. São Paulo: Brasiliense, 1991.

CHAUI, Marilena. A universidade em ruínas. In: TRINDADE, Heitor. (Org.). Universidade em ruinas: na república dos professores. Petrópolis: Vozes; Rio Grande do Sul: Cipedes, 1999. p. 211222. 
CHAUI, Marilena. Cultura e democracia - o discurso competente e outras falas. 8. ed. São Paulo: Cortez, 2000.

CUNHA, Luiz Antonio. A universidade temporã. Rio de Janeiro: Francisco Alves, 1989.

DALBEN, Ângela F. Conselho de classe e avaliação. Campinas: Papirus, 2004.

DIAS SOBRINHO, José. Universidade e avaliação - entre a ética e o mercado. Florianópolis: Insular, 2002.

FREITAS, Luiz Carlos de. Crítica da organização do trabalho pedagógico e da didática. Campinas: Papirus, 2003.

FRIGOTTO, Gaudêncio. A crise do trabalho assalariado e perspectivas de uma nova cultura de relaçôes de produção. Brasília: Unesco; Ministério do Trabalho, 1999.

HEYMANN, Louis; ALBERTI, Victor. (Orgs.). Trajetórias da universidade privada no Brasil. Brasília: Capes; Fundação Getúlio Vargas, 2002.

LAUAND, Jean. Vigência e educação - a ditadura da extroversão. Videtur, Porto: IJI; Cemoroc; Feusp, n. 26, p. 5-20, 2004.

LEITE, Denise (Coord.). Inovação \& avaliação institucional. Efeitos e mudanças na missão das universidades contemporâneas. Porto Alegre: Evangraf, 2002.

OLIVEIRA, Valeska Fortes de. Glossário. In: MOROSINI, Marília (Org.). Enciclopédia de pedagogia universitária. Porto Alegre: Fapergs; Ries, 2003. p. 267-278.

POPKEWITZ, Thomas. A profissionalização e a formação de professores: algumas notas sobre a sua história, ideologia e potencial. In: NÓVOA, Antonio (Org.). Os professores e a sua formação. Dom Quixote: Lisboa, 1992. p. 159-177.

RATINOFF, Leon. Inseguridad mundial: la cultura de la mundialización. Perspectivas, Paris: Unesco; OIT, n. 94, p. 27-31, 1995.

SAUL, Ana Maria. Avaliação emancipatória. Desafio à teoria e à prática de avaliação e reformulação de currículo. São Paulo: Cortez. 2000.

SCHWARTZMAN, Simon. O ensino superior no Brasil- 1998. Brasília: INEP, 1999.

SEVCENKO, Nestor. O professor como corretor. In: Caderno Mais. Folha de São Paulo. 4 jun. 2000. p. 17.

SGUISSARDI, Valdemar. A educação superior privada no Brasil: novos traços de identidade. In: (Org.). Educação superior: velhos e novos desafios. São Paulo: Xamã, 2000, p. 158-177.

SILVA JÚNIOR, José dos Reis; SGUISSARDI, Valdemar. Novas faces da Educação Superior no Brasil-Reforma do Estado e mudanças na produção. Bragança Paulista: Edusf, 2000.

THAYER, Willy. A crise não moderna da universidade moderna. Trad.: Rômulo Monte Alto. Belo Horizonte: EdUFMG, 2002.

TRIGUEIRO, Michelangelo Giotto Santoro. Ensino superior privado no Brasil. Brasília: Paralelo 15; São Paulo: Marco Zero, 2000.

VÁZQUEZ, Adolfo Sanches. Filosofia da práxis. Trad.: Luiz Fernando Cardoso. 2. ed. Rio de Janeiro: Paz e Terra, 1977. 
The college of education of a state university and the evaluation of its academic work: some repercussions

Abstract

The present study shows the results of research carried out with the objective of analyzing the possible repercussions of the evaluation of the work conducted by the teaching staff of the College of Education of a public university, not only in the pedagogical area, but also in the field of teacher education. The context of the Brazilian university was considered when interpreting the perceptions of both students and professors regarding the pedagogical work carried out by both categories. Some measures were pointed out as suggestions: organize a forum for debates; analyze the results of the study individually and collectively; improve not only the process, but also the tools used for evaluation, make an effort to constitute a new institutional culture for evaluation.

Keywords: University. Evaluation. Teacher education.

\section{La faculté d'éducation dans une université publique et l'évaluation du travail des professeurs : quelques répercussions}

Résumé

Cette étude présente les résultats d'une recherche réalisée dans l'objectif d'analyser les possibles répercussions de l'évaluation du travail des professeurs développé dans la Faculté d'Éducation d'une université publique, tant sur le plan pédagogique comme sur le plan de la formation des maîtres. Le contexte vécu par l'université brésilienne a été considéré pour interpréter les perceptions des professeurs et des étudiants quant au travail pédagogique réalisé par les deux catégories. Quelques acheminements ont été proposés comme suggestions : viabiliser un forum de débats; analyser les résultats individuel et collectivement; améliorer non seulement le processus mais aussi les instruments d'évaluation; faire un effort pour constituer une nouvelle culture institutionnelle d'évaluation.

Mots clefs: Université. Evaluation. Formation des maîtres.

\section{La facultad de educación de una universidad pública y la evaluación del trabajo docente: algunas repercusiones \\ Resumen}

El estudio presenta los resultados de una investigación realizada con el objectivo de analisar las posibles repercusiones de la evaluación del trabajo docente desarrollado en la facultad de educación de una universidad pública, tanto en el trabajo pedagógico como en la formación docente. Fue considerado el contexto vivido por la universidad brasileña para interpretar las percepciones de profesores y alumnos acerca del trabajo pedagógico desarrollado por ambos. Algunos encaminamientos pudieron ser apuntados como sugestión: viabilizar foros de debate; analisar los resultados individual y colectivamente; perfeccionar tanto el proceso como los instrumientos de evaluación, desarrollar esfuerzos para constituir una otra cultura institucional de evaluación.

Palabras-clave: Universidad. Evaluación. Formación docente. 